\title{
Important Points to Design Hospital Information System
}

\author{
Hamid Moghaddasi* \\ Department of Health Information Technology and Management, Shahid Beheshti University of Medical Sciences, Tehran, Iran
}

Submission: January 02, 2018; Published: January 24, 2018

*Corresponding author: Hamid Moghaddasi, Associate Professor in Health Information Management and Medical Informatics, Department of Health Information Technology and Management, College of Paramedical Sciences, Shahid Beheshti University of Medical Sciences, Tehran, Iran, Email: moghaddasi@sbmu.ac.ir

\section{Editorial}

Health care organizations, one of the most common of which being hospitals, are multi-specialized organizations. This attribute makes them not to be considered as a single entity, but as multiorganizational entities. The multi-specialized nature of health care institutions shows their complexity, and makes it difficult to calculate their performance. On the other hand, the existence of many subsets and the variety of existing relationships, is a major obstacle for developing a paper-based information system that can cover this very complex institution [1-3].

The use of computers in hospitals was first reported in the statistics unit and then the accounting unit of Thousand Beds Philadelphia Hospital in 1954. But when in the early 1960s it was used in the radiology department (a medical unit), the developed software was called the Hospital Information System (HIS). Laboratory competition with radiology has stopped the use of the term "HIS" for the information system software belonging to each clinical department. Thus the name of the relevant department should be assigned: for example, the radiology information system, or the laboratory information system. The growth of using computers to develop information systems for other parts of the hospital was so rapid that, prior to the 1970 s, most of the clinical departments enjoyed computer information systems $[4,5]$.

The nature and limitations of multi-user computer services during that period, the lack of network-oriented viewpoints, and the lack of information theories, as well as theories about designing information systems, are important factors in not developing a comprehensive information system that can handle all current activities in health care institutions or hospitals. Since the beginning of the 1980s, mass production of personal computers has led to the network concept and the possibility of designing network-based software based on organizational and functional models $[5,6]$.

Also, information theories such as the data-to-knowledge continuum, the data-to-wisdom continuum, developed in 1986 (by Bloom) and 1989 (by Nelson) respectively, caused health care institutions to literally benefit from the comprehensive computerized information system. Reasonable price and small size of personal computers in comparison to multiuser type, are important factors for implementing computer information systems at all the hospital units, both administrative and clinical. The emergence of network concept after producing the personal computers, and the possibility of designing network-based software, is one of the main reasons for the developing HIS $[7,8]$.

The undeniable fact is that, if there was no computer help, health care institutions were never able to have comprehensive information systems. Because the physical nature of the paper proposes many limitations in the establishment of relations; therefore, the development of HIS is not fully feasible [5-7].

The design of a HIS requires the identification of an applicable expectation or its proper understanding. That is, an applicable definition of HIS as a general scheme introduced as a meta-model and defines its overall architecture. The evolutionary flow of meta-models proposed about HIS indicates the evolutionary trend expected by its owners about application of such a system. During the two decades since the beginning of the 1980s, organizational, functional, data model, technical, business process, and enterprise meta-models were introduced, and each one shows its applicable expectation. The most comprehensive HIS architecture that outlines various uses of a hospital information system is the enterprise meta-model [8].

However, for designing a hospital information system, a combination of meta-models (preferably enterprise metamodel) as a fundamental HIS architecture is required to allow the expected application of the system $[8,9]$.

In addition to the existence of the management information systems to support decision-makers in the administrative and clinical departments, another point to consider through designing HIS is that each of the two main parts of the hospital information system (including the administrative information system and clinical information system) should have a Decision Support 
System. Also, the interoperability of the two systems, which are considered as two brain hemispheres, is an absolute and necessary principle. This way, in addition to the possibility of exchanging the data required, it is possible to combine data of the two administrative and therapeutic areas to support organizational decisions that are based on performance questions [5-7,10].

Another feature that should be taken into consideration is that the medical information system cannot be regarded as an entirely distinct entity, like other clinical information systems such as nursing, pharmacy, lab, radiology, nutrition. This system, due to the current and ongoing nature of the care process, focuses on diagnostic and therapeutic decisions of physician (as the director of the care team) and is seen in all clinical information systems. In other words, the architecture of the medical information system is integrated with the architecture of other clinical information systems [5,7-9].

One of the most important features that a HIS should have is the ability to provide an electronic medical record as one of the important outputs of the information system. The important point is that the content of this file should be specified at an acceptable level or standard, so that any report is not interpreted as a patient record. Definition provided for the medical records content that has been developed by international organizations such as WHO, $\mathrm{AHA}$, and IOM as a standard is that: all documented facts relating to all services that have been taken for the patient from admission to discharge $[5,6,11]$.

The existence of an encoding system is one of the significant coordinates of a HIS. It provides a variety of clinical and nonclinical data categorization, as well as a variety of useful reports of those categories for strengthening registry systems and the use of health insurance organizations, research institutes, and policy making authorities [12].

One of HIS's features is the availability of clinical decisionmaking systems to facilitate the decision-making process on diseases that are not easily diagnosed, as well as to improve patient care management. Also, the use of dashboard software for the use of different levels of management in the administrative and therapeutic areas will facilitate the implementation of management and increase the efficiency of decision making [13].

Providing the possibility of connecting all digital devices, particularly point of care system (POC) such as diagnostic and therapeutic, is very important when considering the design of the hospital information system in order to transfer data to use them $[14,15]$.
Because the software of a hospital information system is very extensive and includes many software segments with a variety of communications, the Component-based method should be used in conjunction with Spiral and Evolutionary techniques for producing such a complex and large software. Considering this point, the software will develop accordance with all changes of healthcare institution, in addition to increasing its efficiency. Compliance with this rule ensures the overall quality of the technical design of the HIS software [16].

\section{References}

1. Lipsitz, Lewis A (2012) Understanding health care as a complex system: The foundation for unintended consequences. JAMA 308(3): 243-244.

2. James BW, Zimmerman B, Dooley K (2003) Health care organizations as complex adaptive systems. San Francisco, USA, pp. 253-288.

3. McDaniel RR, Driebe DJ, Lanham HJ (2013) Health care organizations as complex systems: new perspectives on design and management. Adv Health Care Manag 15: 3-26.

4. (2014) The History and Evolution of Healthcare Information Systems, Northern Virginia Community College, Virginia, USA.

5. Merida J (2002) Information management for health professions. Cengage Learning, USA.

6. Wager KA (2005) Managing health care information systems: A practical approach for health care executives. Jossey-Bass, USA.

7. Englebardt SP (2001) Health care informatics: An interdisciplinary approach, USA.

8. Haux R, Winter A, Ammenwerth E, Brigl B (2004) Strategic information management in hospital: An introduction to hospital information systems. Springer.

9. Degoulet P, Fieschi M (1997) Introduction to clinical informatics. Springer.

10. Lucey T (2000) Management information systems. New York, USA.

11. Landis LZ, Mello-Thoms C, Visweswaran S, Crowley R (2010) Using electronic medical records to measure guideline adherence in lowresource settings.

12. Spyns $P$ (2000) Natural language processing in medicine: Design, implementation and evaluation of an analyzer for dutch. Leuven University Press, Belgium.

13. Robert R (2011) Clinical decision support: What it is and how to use It. USA.

14. Montoya ID, Carlson JW (1996) Point-of-care systems, informatics, and health care deliver. Health Care Superv 15(2): 17-26.

15. Clarke EM (2008) Point of care connectivity.

16. Blake MB (2006) Component-based design and development for robust medical applications. USA. 
This work is licensed under Creative Commons Attribution 4.0 License DOI: $10.19080 / J O J N H C .2018 .06 .555680$
Your next submission with Juniper Publishers will reach you the below assets

- Quality Editorial service

- Swift Peer Review

- Reprints availability

- E-prints Service

- Manuscript Podcast for convenient understanding

- Global attainment for your research

- Manuscript accessibility in different formats

( Pdf, E-pub, Full Text, Audio)

- Unceasing customer service

Track the below URL for one-step submission https://juniperpublishers.com/online-submission.php 